\title{
Review of Aetiology and Management of Testicular Abscess and Case Reports on Testicle Sparing Management of Testicular Abscess
}

\author{
Devendra K. Prajapati ${ }^{* 1}$, Kapil Rampal ${ }^{1}$, Jyoti M Prajapati ${ }^{2}$.
}

${ }^{* 1}$ Senior Resident Department of Surgery, Deendayal Upadhyay Hospital, New Delhi, India.

2 Scholar in Computer Application.

\section{ABSTRACT}

\begin{abstract}
Testicular abscess is a rare surgical emergency encountered by a surgeon. Very little documentation is available in literature. This is reason has contributed for this review article about testicular abscess. Testicular abscess develops as a complication in about 4-5\% case of acute scrotum like acute epididymorchitis, testicular trauma or instrumentation. Single radiological investigation, USG of inguino-scrotal region is sufficient to diagnose testicular abscess. Both active surgical drainage at first go and conservative management with empirical antibiotics and serial radiological monitoring via USG have been advocated, but finally about $50 \%$ patient needs incision and drainage or orchidectomy. We have managed two patient of testicular abscess with testicle sparing incision \& drainage. In one case, after drainage primary closure of skin was done with drain placement and in the other case skin had to be debrided and wound was kept open, later secondary closure was done. In both cases testicles spared viable and all confirmed by USG color Doppler in follow up.

Primary closure of wound after incision \& drainage depends on condition of skin. Testicular abscess without skin changes can go through primary closure after drainage

KEY WORDS: Testicular Abscess, Epididymorchitis, Acute Scrotum, UTI, M anagement of Testicular Abscess, USG Testicular Abscess, Orchidectomy.
\end{abstract}

Address for correspondence: Dr. Devendra K Prajapati, WZ423 A Nanakpura Harinagar, New Delhi-110064, India. E-Mail: dr.dev1982@gmail.com

\begin{tabular}{|c|c|c|}
\hline \multicolumn{3}{|c|}{ Online Access and Article Informtaion } \\
\hline \multirow{2}{*}{$\begin{array}{c}\text { Quick Response code } \\
\text { Dol: } 10.16965 \text { ijims.2016.132 }\end{array}$} & \multicolumn{2}{|c|}{$\begin{array}{c}\text { International Journal of Integrative Medical Sciences } \\
\text { wwww.imedsciences.com }\end{array}$} \\
\hline & $\begin{array}{l}\text { Received: 13-06-2016 } \\
\text { Reviewed: 13-06-2016 }\end{array}$ & $\begin{array}{l}\text { Accepted: 20-06-2016 } \\
\text { Published: 31-07-2016 }\end{array}$ \\
\hline Source of Funding: Self & & terest: None \\
\hline
\end{tabular}

\section{INTRODUCTION}

Testicular abscesses are a very rare clinical finding. These are usually associated with epididymorchitis with treatment failure [1]. Acute epididymorchitis occurs in $0.29 \%$ of young sexually active males with radiologically normal inguinoscrotal region [1]. Testicular abscess is an uncommon complication affecting $4-5 \%$ of clinically diagnosed males with severe epididymorchitis [2]. Epididymorchitis is most often due to the retrograde transmission of organisms from the vast deferens whereas haematogenous spread is rare. In $80 \%$ cases the causative organism are according to the age of the patient. In younger and older age groups $E$. coli is supposed to be commonest pathogen while in the sexually active age group, $\mathrm{C}$. Trachomatis is the commonest bacteria seen $[3,4]$.

Causative factors: Acute scrotal pain is a common cause to attend hospital in an emergency; however, there are many problems to find out the localization of pathology in inguinoscrotal region. This has been suggested the following paradigm of zonal classification of the inguinoscrotal region [5]: 
Zone I: This zone includes deep ring via the inguinal canal, at the conclusion of the spermatic cord e.g. Varicocele, Incarcerated Hernia, Trauma or Torsion of Undescended Testicle

Zone II: This zone includes the scrotum, subcutaneous tissue and tunica vaginalis e.g. bites, Scrotal Wall Cellulitis, Fournier's Gangrene, Lacerations, and Hematocele etc.

Zone III: This zone defines the testicle e.g. Testicular Torsion, Orchitis, Testicular Abscess etc.

Zone 1V: This zone defines the epididymis and appendix of epididymis e.g. Epididymitis, Torsion of Appendix of Epididymis.

Testicular abscess is a rare surgical condition of Zone III of inguinoscrotal region, which has multifactorial reasons of origin $[3,4,6]$.

\section{INFECTIVE:}

a. Acute: commonly testicular abscess preceded by acute epididymorchitis which could not be processed properly. Another is a viral infection like Mumps etc.

b. Chronic: tuberculosis or fungal infection, which is common in immunocompromised individuals.

c. Secondary: ruptured acute appendicitis drainage into scrotum through a patent processus vaginalis may precede to testicular abscess.

TRAUMATIC: testicular trauma preceded to hematoma and traumatic infarction (secondary to testicular torsion or mumps) may convert to testicular abscess if do not treat properly.

CHEMICAL: chemicals likely secondary to brachytherapy to prostatic carcinoma.

Post instrumentation: like catheterization results CAUTI followed by epididymorchitis or testicular abscess rarely.

Testicular abscess can also happens as a result of extravasation of infected urine from the urethra in patients with a urethral stricture and neurogenic bladder using an external collection device.

Pathology: Testicular abscesses are most commonly precedes to epididymorchitis. Thus, common pathogenic organisms are [7]:
Sexually transmitted: Neisseria gonorrhoea and Chlamydia trachomatis are common Enterococcus spp. Coliforms,_Staphylococcus spp. (less common), and Streptococcus spp. (less common). Staphylococcus infection common in instrumen-tation and catheterization $[16,18]$.

\section{Management:}

Diagnosis: A patient presenting with a testicular abscess may cause symptoms linked to the etiology of the abscess like swelling, pain and fever. Another may manifestation of a urinary tract infection or sexually transmitted disease symptoms, like fever, frequency, urgency, dysuria, penile discharge.

On physical examination the scrotum is often enlarged, erythematous and tender. Scrotum may fluctuant and warm. Tenderness of the affected epididymis and/or testis may also be present. The overlying skin will be oedematous and fixed to epididymis, if it is followed by epididymitis [8].

A physical examination and laboratory tests should conducted to obtain a level of infection and the testicular abscess. Laboratory tests (hematological tests) can include a urinalysis, urethral swab culture for STDs, and for gram staining and imaging tools, such as an ultrasound and color doppler.

\section{Ultrasound features consist of [9-12]:}

1. Altered architecture either cystic, solid or isoechoic to rest.

2. Centre abscess will be avascular and rest of tissue hyper vascular on echogenicity.

3. May be intrascrotal fluid or rarely gas collection along with scrotal wall thickness.

After a proper diagnosis has been found, adequate treatment can commence. M RI pelvis rarely needed for diagnosis where CA testis is suspected [13].

Treatment: Classically testicular abscess is treated by appropriate antibiotics alone or with surgical drainage if necessary [14]. If a conservative approach is attempted (i.e. empirical medical therapy) then serial ultrasound examinations should be performed to ensure that the abscess does not progress. Severe cases may necessitate orchiectomy [15]. 
Chronic testicular abscess usually requires orchidectomy as in most cases, no viable testicular tissue could be obtained [15]. If successfully treated, the testis can return to near normal. In some cases, testicular atrophy develops, mostly when swelling is more severe.

Case Report I: A 55 year old male patient came in the emergency surgery ward with complain of dull aching pain left scrotum since 1 month. This pain increases in intensity since 3 days associated with high grade fever, dysuria and frequency of urine. The patient does not have a history of per urethral discharge or promiscuous behaviour. The patient also does not have a history of any other medical co-morbidity.

On examination patient's general condition was good and vitals were all stable. No pallor, cyanosis, icterus or lymphadenopathy. Rest of the systemic examination was essentially within normal limits.
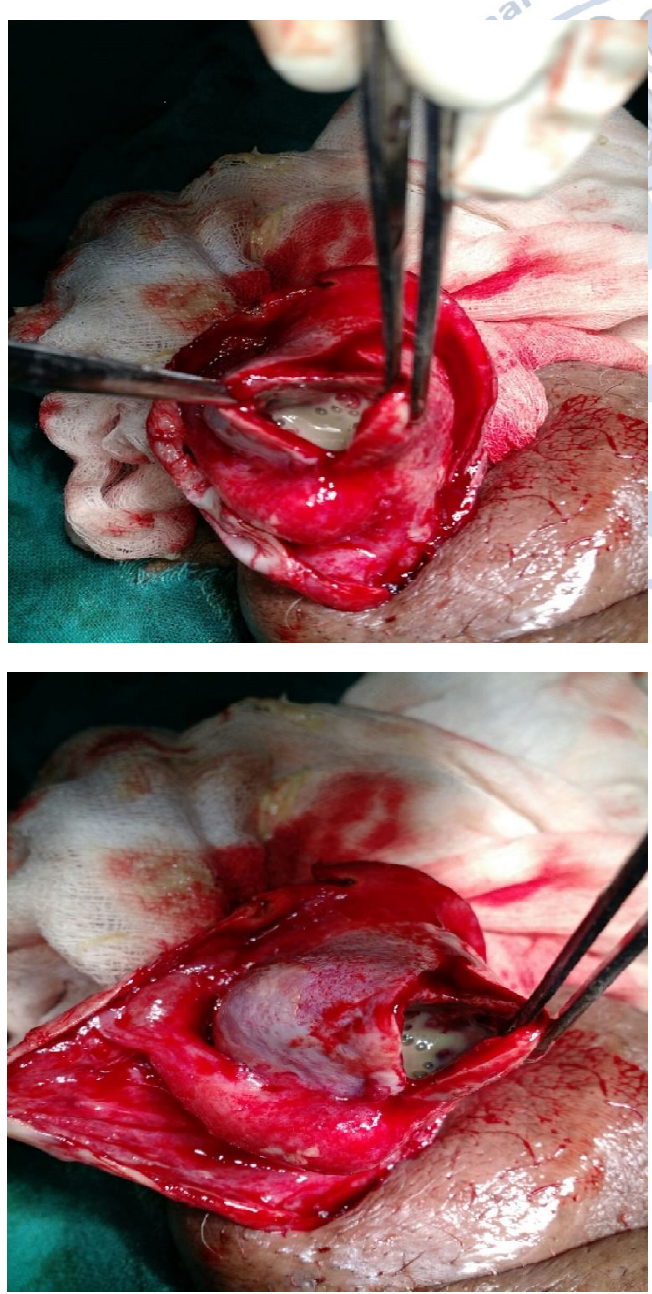

On local examination: left hemiscrotum was enlarged to three times the normal, overlying skin was erythematous and shiny and local temperature was raised. The swelling was tender, fluctuant, with absent cough impulse and 'getting above' the swelling was present. The spermatic cord was bulky, tender and adherent to overlying skin. There were no scars, sinuses, dilated veins or hernia.

Later on a patient admitted in the emergency surgery ward and initially following investigations performed.

Table 1: Showing the findings on investigations.

\begin{tabular}{|c|c|}
\hline Investigations & Value \\
\hline TLC & 15000 \\
\hline DLC & N80\% L15\% E03\% M 02\% \\
\hline Urine routine microscopy & S-8 pus cells \\
\hline Pus culture sensitivity & Staphylococcus \\
\hline USG inguinoscrotal & $\begin{array}{r}\text { Left testicular abscess of volume } 20 \mathrm{ml} \\
\text { Left epididymorchitis with funiculitis } \\
\text { Left mild to moderate echogenic hydrocele }\end{array}$ \\
\hline
\end{tabular}

A diagnosis of testicular abscess was made on the basis of routine investigation and USG inguinoscrotal region and patient planned for incision and drainage.

Patient shifted to OT table after proper preoperative preparation. With induction of anaesthesia, patient laid supine and cleaning, painting and draping done. Left scrotal incision given and layer by layer dissection done. Tunica vaginalis sac opened and approx. $25 \mathrm{ml}$ serous collection drained. Further testis was exposed and examined properly, it was fluctuant and on needle tapping frank pus was aspirated. A longitudinal incision was made over it and approx. $20 \mathrm{ml}$ pus drained out. Pus was sent for culture sensitivity and AFB staining. [Figure 1 , 2]

Abscess cavity curetted for dead and necrotic tissue and washed with povidine and normal saline. Rest of sac and cavity also washed with same. Eversion of sac was performed and a suction drain placed by making a systematic arrangement that tip of drain was inside the testicular abscess cavity and ran via scrotal cavity to out of scrotum. Wound closed in layers and dressing applied.

Postoperatively patient kept on cephalosporin, aminoglycoside and metronidazole combination and also oral doxycycline was added from next day onwards for 14 days. Patient improved well and the drain was removed on the 5th postoperative day. 
Fig. 3: Showing the Ultrasound Diagnostics.

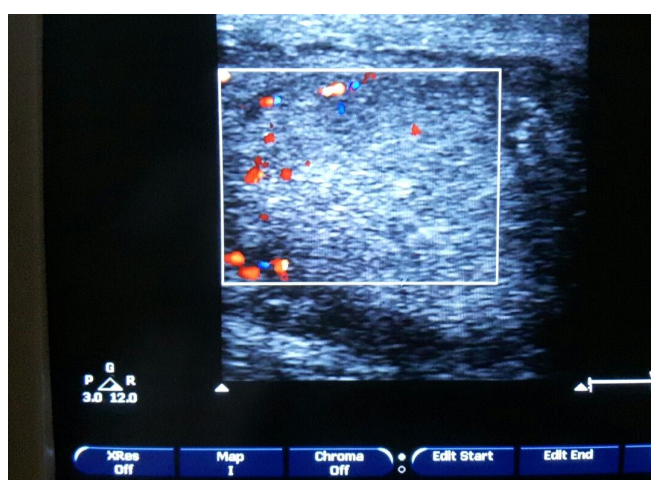

Follow up USG inguinoscrotal region performed after 02 weeks showed both testis to be viable with no collection and minimal inflammatory changes. [Figure 3]

Patient was followed up till 6 weeks with weekly USG monitoring. Till being follow up testis found viable and healthy but after 06 weeks the patient was lost to follow up.

Case Report 2: A 54 years old male attended surgery emergency with complain of left scrotal swelling, pus discharge and fever with chills. No history of dysuria, per urethral discharge and promiscuity was reported. Patient also did not have any accompanying medical co-morbidity.

On examination patient was in good general condition and had stable vitals. There was no pallor, cyanosis, icterus or generalized lymphadenopathy. Systemic examination was essentially within normal limits.

On local examination scrotum was enlarged, overlying skin breeched with pus oozing out, erythematous and tender, subcutaneous collection with fluctuation present, the spermatic cord was bulky and tender.

Table 2: Showing the findings on investigations.

\begin{tabular}{|c|c|}
\hline Investigations & Value \\
\hline TLC & 18000 \\
\hline DLC & N78\% L22\% E02\% M 03\% \\
\hline $\begin{array}{c}\text { Urine routine } \\
\text { microscopy }\end{array}$ & $2-3$ pus cells \\
\hline $\begin{array}{c}\text { Pus culture } \\
\text { sensitivity }\end{array}$ & E.coli \\
\hline $\begin{array}{c}\text { USG } \\
\text { inguinoscrotal }\end{array}$ & $\begin{array}{c}\text { Left testicular abscess of volume 3-5ml } \\
\text { Left epididymorchitis with funiculitis } \\
\text { Subcutaneous collection }\end{array}$ \\
\hline
\end{tabular}

Int J Intg M ed Sci 2016;3(7):332-36. ISSN 2394 - 4137
Patient was admitted in emergency surgery ward and routine investigation and USG inguinoscrotal region to assess underlying pathology, were performed. [Table 2]

Based on clinical examination and investigations, a diagnosis of testicular abscess was made and the patient planned for incision $\&$ drainage.

Fig. 4: Showing left scrotum draining procedure.

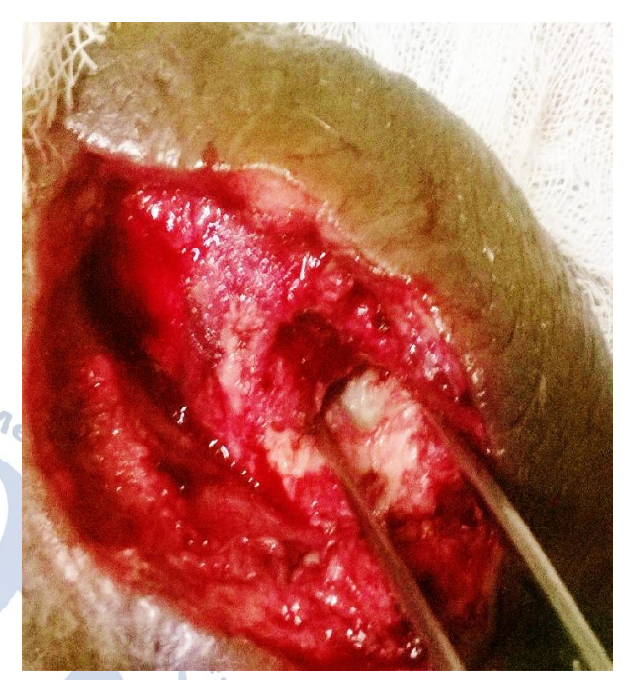

Patient shifted to OT after due preoperative preparation. Incision made over left scrotum drained approx. $20 \mathrm{ml}$ subcutaneous pus collection. Necrotic skin was debrided and further tunica vaginalis sac and tunica albuginea opened. Approx. $10 \mathrm{ml}$ testicular abscess was drained, all dead necrotic tissue debrided and cavity washed with povidene-normal saline. Wound kept open and dressing done.

Post operatively patient kept on 3rd generation cephalosporin, aminoglycoside and metronidazole combination with regular aseptic dressings.

Wound granulated well and the testis was viable on USG performed after two weeks. Secondary suturing of wound done on 14th post-operative day. Thereafter the patient was discharged and on regular follow up ultrasounds for 06 months the testis was found to be healthy and viable.

\section{DISCUSSION}

Testicular abscess is very rare surgical emergency which is commonly accompanied by acute scrotum. Epididymorchitis is the commonest pathology underlying acute scrotum followed by trauma. Acute epididymorchitis is caused by Chlamydia Trachomatis and N Gonorrhea 
in sexually active age groups and by E.coli, Staphylococci, and Streptococci in younger and older age groups $[3,4,6]$.

Acute epididymorchitis may result in a testicular abscess in approx. $4-5 \%$ males if remain untreated or improperly handled [2].

Our first case presentation is in elder age group (age 55 years) where Staphylococcus aureus is the causative organism. Staphylococcus aureus is an uncommon organism for UTI [16-17]. Coll PP et al had concluded in their study that urinary tract instrumentation and catheterization contribute to ascending infection with Staphylococcus aureus [18].

The USG inguinoscrotal region is sufficient investigation for diagnosis of testicular abscess. Usually testicular abscess may be managed by empirical antibiotics with serial monitoring by USG and ultimately patient may need incision and drainage or orchidectomy. After drainage wound can be closed primarily but it depends on scrotal skin changes. We have performed incision and drainage followed with primary closure of the wound in the first case and wound kept open in the second case. In both cases testis spared viable after regular follow-up.

\section{CONCLUSION}

The testicular abscess is rare clinical entity and is even rare amongst cases presenting with acute scrotum. The condition can be managed by incision $\&$ drainage with testicle sparing and either primary closure of wound or to be kept open. Post-operative serial ultrasonography is the preferred modality of evaluation. Primary closure of wound depends the presence of a healthy scrotal skin.

\section{REFERENCES}

[1]. K. M. Desai, J. C. Gingell, and J. M. Haworth, Localised intratesticular abscess complicating epididymoorchitis: the use of scrotal ultrasonography in diagnosis and management, British Medical Journal, 1986;292(6532):1361-1362.
[2]. Luzzil GA and O'Brien TS. Acute epididymitis. BJU International 2001;87:747-755.

[3]. Dogra, V.S., et al., Sonography of the scrotum. Radiology, 2003;227(1):18-36.

[4]. Thakur, A., et al., Scrotal abscess following appendectomy. PediatrSurgInt, 2001;17(7):569-71

[5]. SKhan, J Rehman, B Chughtai, D Sciullo, E M ohan, $H$ Rehman. Anatomical Approach to Scrotal Emergencies: A New Paradigm for the Diagnosis and Treatment of the Acute Scrotum. The Internet Journal of Urology. 2009;6(2).

[6]. Granados Loarca, E.A., [Testicular abscess: a manifestation of tuberculosis]. ActasUrolEsp, 1998;22(4):381-3.

[7]. Wilks D, Farrington $M$, Rubenstein $D$. The infectious diseases manual. Wiley-Blackwell. 2003; ISBN: 063206417X.

[8]. Bodner D. Resnick MI, Novick AC. Scrotal abscess. In: Urology Secrets, eds. 3rd. Hanley and Belfus Inc. 2003;70:270.

[9]. Bluth El, Benson CB, Ralls PW et-al. Ultrasonography in Urology. Thieme. ISBN: 1588906094.

[10].Berman JM, Beidle TR, Kunberger LE et-al. Sonographic evaluation of acute intrascrotal pathology. AJR Am J Roentgenol. 1996;166(4):85761.

[11]. Dalrymple NC, Leyendecker JR, Oliphant M. Problem Solving in Abdominal Imaging. Mosby Inc. 2009; ISBN: 0323043534.

[12]. Zagoria RJ. Genitourinary radiology, the requisites. M osby Inc. 2004; ISBN: 0323018424.

[13]. http://www.mademan.com/mm/how-treat-scrotalabscess.html\#ixzz3ySnKOSeK

[14]. Granados Loarca, E.A. et al. Epididymo.testicular abscess. Arch EspUrol, 1994;47(6):553-6.

[15]. Slavis, S.A., J. Kollin, and J.B. Miller, Pyocele of scrotum: consequence of spontaneous rupture of testicular abscess. Urology. 1989; 33(4): p. 313.6.

[16]. Demuth PJ, Gerding GN,Crossley K. Staphylococcus aureus bacteriuria. Arch Intern Med. 1979;139:7880.

[17].Barrett SP, Savage MA, Rebec MP, Guyot A, Andrews N, Shrimpton SB. Antibiotic sensitivity of bacteria associated with community-acquired urinary tract infection in Britain. J Antimicrob Chemother. 1999;44:359-65.

[18]. Coll PP, Crabtree BF, O'Connor PJ, Klenzak S. Clinical risk factors for methicillin-resistant Staphylococcus aureus bacteriuria in a skilledcare nursing home. Arch Fam M ed. 1994;3:357-60.

\section{How to cite this article:}

Devendra K. Prajapati, Kapil Rampal, Jyoti M Prajapati. Review of Aetiology and Management of Testicular Abscess and Case Reports on Testicle Sparing M anagement of Testicular Abscess. Int J Intg M ed Sci 2016;3(7):332-336. DOI: 10.16965/ijims.2016.132 